\title{
Objeto Pedagógico: Relatando o Ensino de Arte em Classes Inclusivas ${ }^{1}$
}

$\operatorname{Prof}^{a}$ Dr $^{\mathrm{a}}$ Maria Cristina da Rosa Fonseca da Silva ${ }^{2}$, Sabrina Maurilia dos Santos ${ }^{3}$,

Daniela Almeida Moreira ${ }^{4}$.

Resumo: Este estudo investigou os procedimentos didático-pedagógicos para o uso de objetos pedagógicos utilizados pelos professores de artes na grande Florianópolis. Outro aspecto identificado na pesquisa foram os conceitos de inclusão utilizados pelos professores de arte, que fundamentam a prática docente destes profissionais. $\mathrm{Na}$ intenção de socializar as análises a partir das instituições visitadas, este artigo sistematiza como se dá a inclusão no espaço escolar e o processo utilizado pelos professores de arte para garantir a participação dos alunos com necessidades especiais.

Palavras-Chave: Educação inclusiva - ensino de arte - objeto pedagógico metodologia de ensino.

\section{Apresentação:}

A pesquisa foi desenvolvida em 7 escolas, neste contexto foram entrevistados 9 professores de artes e 12 estudantes com necessidades especiais. No que se refere às saídas de campo aos ambientes escolares, cabe ressaltar que 3 das escolas observadas pertencem à rede municipal de ensino de Florianópolis, 1 de São José e 2 delas são do governo federal. Quanto aos profissionais que atuam diretamente junto às professoras de artes, no auxílio às turmas, quando há estudantes com necessidades educacionais especiais, apenas 1 das instituições não dispõe deste tipo de suporte. Todas as professoras de artes, que lecionam em cada escola são licenciadas em Artes Plásticas, porém, somente 1 obteve uma formação que já tratava o tema da inclusão na Universidade.

Com base nos 12 estudantes de arte observados, 4 tinham como diagnóstico paralisia cerebral, 3 baixa visão, 3 autistas, 3 surdos, 1 cego, 1 com deficiência mental e 1 com esclerose tuberosa e autismo.

\footnotetext{
${ }^{1}$ Projeto de Pesquisa: Construção metodológica do fazer pedagógico de arte: desafios da inclusão Centro de Educação a Distância - CEAD - UDESC.

${ }^{2}$ Orientadora - Departamento Pedagógico - DPED - CEAD/UDESC - Mestrado em Artes Visuais CEART-UDESC

${ }^{3}$ Bolsista de Iniciação Científica. PROBIC.

${ }^{4}$ Bolsista de Iniciação Científica. PIVIC.
} 
Entre os mecanismos de coleta de dados utilizados para esta pesquisa, destaca-se o uso de entrevista semi-estruturada com os professores de artes e as observações, que totalizaram 8 para cada estudante. Com base nos dados levantados, faz-se um relato do desenvolvimento deste processo de inclusão dos estudantes com os professores, colegas de classe e a escola como um todo. Ressaltando também os aspectos da realidade das escolas de Florianópolis, onde a inclusão de alunos com necessidades educacionais especiais ainda constitui-se uma barreira para as partes envolvidas.

Optou-se neste texto por direcionar a análise da realidade das escolas públicas de Florianópolis, que além de apontar o perfil dos professores de artes, buscará um foco maior nas aulas e nos estudantes observados. Para sistematizar os dados de pesquisa utilizou-se uma tabela fundamentada nestas observações, organizada por categorias de análise tais como, visão de inclusão da escola e do professor, materiais educativos e a arte inserida neste contexto.

Não cabe a esta proposta fazer uma comparação entre escolas, alunos e professores, mas sim refletir sobre o processo e as concepções de inclusão/integração no conjunto da escola, analisando assim o procedimento e as metodologias educacionais utilizadas pelas professoras de artes junto aos estudantes com necessidades especiais e, principalmente a relação destes junto ao espaço escolar.

\section{A realidade das Escolas Públicas: localizando o contexto desta pesquisa}

Analisando o contexto da inclusão observa-se que as escolas públicas apresentam de maneira geral dificuldades de aplicar as políticas públicas criadas pelos governantes.

Quando se pensa educação inclusiva no espaço escolar, podemos entender que há uma ponte estabelecida entre inclusão e integração, neste caso, Bayer explana que “(...) uma não elimina a outra, pois enquanto uma busca garantir o direito ao acesso, a outra procura garantir a qualidade das relações que se estabelecem dentro da escola". (apud Lopes, p.3, 2007). No entanto, pode se dizer que esta análise não é consensual entre os educadores. No centro do debate dos movimentos sociais organizados e na educação algumas análises responsabilizam a integração como uma orientação que coloca a criança com necessidades especiais na escola, mas não proporciona uma inclusão de fato. 
No que diz respeito à inclusão, de acordo com Diário Catarinense (18/06/08) este é um assunto já explanado em Santa Catarina desde 2006, onde ficou assegurado aos alunos com necessidades especiais um segundo professor e um serviço de atendimento especializado para os diversos casos. A matéria ressalta também que o preconceito ainda é visto como um obstáculo. Por outro lado, observa-se que os movimentos inclusivos começaram a influenciar a Educação no Brasil a partir da década de 1990, com a aprovação da Declaração de Salamanca que trouxe o tema da "Educação para Todos". Neste caso Santa Catarina está atrasada em relação ao começo do movimento. (FONSECA da SILVA, 2008).

Para que haja qualidade nas relações e o enfrentamento do preconceito na escola, é necessário um trabalho onde a inclusão se estabeleça entre o coletivo envolvido. Onde os estudantes com necessidades educacionais especiais recebam, além do apoio da instituição, o suporte da família e da sociedade. Completando esta idéia, Pereira e Freitas (2006), sugerem que para um ensino ter como finalidade a aprendizagem, não será abdicado a consciência de que todos os estudantes podem aprender, ainda que alguns careçam de alguma adaptação no currículo, mesmo assim, elas explicam que todos poderão ter acesso ao conhecimento produzido - este que será construído socialmente - envolvendo uma união formada pelo aluno, professor, escola e família.

Reflete-se que uma inclusão de forma plena se dá em conjunto, onde o todo poderá aceitar as especificidades de cada um, tendo o apoio necessário para que haja uma troca entre os envolvidos, trabalhando de forma adjacente na questão do preconceito. Assim, pode se dizer que a compreensão da diferença enquanto uma deficiência é um artefato social construído historicamente pelas sociedades, o preconceito desta forma não é algo natural, ele se constitui nas relações sociais de poder, onde as práticas escolares se constituem.

Segundo uma pesquisa realizada por Fonseca da Silva (2007), na rede municipal de Florianópolis, Santa Catarina, apenas os alunos do Ensino Fundamental de $5^{\mathrm{a}}$ a $8^{\mathrm{a}}$ série tem professor de Arte com formação na área. No total são 25 escolas básicas que atendem o ensino fundamental de $5^{\mathrm{a}}$ a $8^{\mathrm{a}}$ série. $\mathrm{O}$ concurso de entrada destes professores é por área, Artes Plásticas, Música e Artes Cênicas. Dos 25 professores que atuavam na rede municipal na época, 15 são de Artes Visuais. Estabelecendo o perfil destes educadores, Fonseca da Silva aponta que uma parte destes professores são graduados em educação Artística e a outra parte apresenta também especialização , mestrado e alguns são mestrando. A autora também observa alguns dados pertinentes a esta análise, 
destacando que à metade dos docentes entrevistados eram substitutos, dado que, segundo ela, desfavorece os resultados da educação continuada, proposta pela secretaria da educação, pois todo ano há uma renovação dos professores de artes. Com base neste estudo percebe-se o baixo número de professores de Artes Visuais, com formação continuada na rede municipal de ensino de Florianópolis. Constata-se também que só terão professores de arte com formação na área os estudantes a partir da $5^{\circ}$ série. Compreendendo a importância da Arte como área de conhecimento e seu potencial de inclusão, uma vez tratada como forma de linguagem que envolve todos os sentidos, conclui-se que os estudantes, não terão esta disciplina na educação infantil e séries iniciais.

\section{Materiais adaptados: métodos inclusivos na arte:}

Pensando em materiais adaptados para trabalhar junto aos estudantes com necessidades educacionais especiais, pode-se identificar o potencial da Arte inserida neste conjunto. Destaca-se que existem possibilidades infinitas de adaptação de materiais para uma construção ilimitada de subjetividade por parte dos estudantes. Pensa-se que as elaborações destes conteúdos podem acontecer com as contribuições das linguagens artísticas como objetivo de inclusão. Ao estudar estas questões, Lopes (2007) nos permite identificar que uma criança com deficiência, seja sensorial, motora, ou cognitiva, pode depender de saberes variados por parte dos educadores, estes, segundo o autor, devem sugerir aos estudantes atividades que acompanhem as leituras subjetivas dos mesmos.

Os materiais abordados aqui devem ser discutidos dentro do ponto de vista da inclusão, aberto a limitação de cada criança, buscando como ponto principal um acesso ao novo, ao diferente. Referente à ação que trata das diferenças, podemos contar com a contribuição de Lopes (2005), que aborda esta questão da seguinte forma:

\footnotetext{
“Acreditamos que, valorizando o papel das diferentes linguagens no processo de constituição dos sujeitos na construção de conhecimentos e na busca de uma relação dialógica e polifônica, poderemos criticamente compreender os modos de significação e percepção do mundo e de sí próprio. O sujeito na sua relação alteritária com o mundo físico e social, participa na produção de signos que não cessam de evoluir, transformando-se e transformando a cultura de uma época”. (Lopes, 2005, p.16)
} 
Baseando-se em Lopes, conclui-se também que sendo a arte uma fonte de conhecimento que envolve todos os sentidos, através da linguagem artística os estudantes poderão desenvolver trabalhos, onde o próprio olhar poderá ser transmitido ao contexto, o que facilita a comunicação com o professor e os colegas de classe. Para os alunos com necessidades educacionais especiais, nas classes de Ensino de Arte, pensa-se que os materiais devem ser adaptados de acordo com a necessidade de cada um. Esta tarefa poderá ser abordada de forma lúdica, pois através da arte a criança, poderá trabalhar todos os sentidos.

No uso de objetos pedagógicos na escola pode-se dizer que há um sentido de aproximação quando estes são utilizados para ampliar os referenciais artísticos das pessoas com necessidades especiais. Neste caso o objeto pedagógico pode se utilizar justamente dos sentidos mais desenvolvidos pelo estudante com deficiência para criar um novo campo de aprendizagem, neste caso de aquisições no ensino de arte. Sobre este tema Fonseca da Silva e Bornelli (2007) apresentam os fatores que ampliam a importância do uso e da investigação dos objetos pedagógicos para o ensino de arte.

\section{Os estudantes com necessidades especiais, diálogos com a docência em arte:}

Como instrumento de coleta de dados, a observação do contexto de classes regulares inclusivas pôde estruturar-se como um roteiro aberto buscando perceber as contribuições metodológicas e para conhecer o contexto inclusivo no ensino de arte. Os dados foram organizados em tabelas que permitem uma melhor visualização, haja visto o modelo de observação descritiva. Neste sentido os dados observados e transcritos foram divididos em quatro tópicos a serem analisados. O primeiro tratava-se da visão de inclusão da escola, de como se dá este processo e o suporte oferecido pela instituição, o segundo tópico sugeria uma análise da formação do professor, o terceiro aspecto a ser investigado nesta pesquisa foram os materiais educativos e a estratégia metodológica do docente, o quarto e último ponto verificado foi a respeito da arte como instrumento de inclusão.

Relatando uma síntese da observação realizada nas escolas observadas, cabe a este espaço a transcrição de alguns momentos pertinentes ao convívio, em específico, junto aos estudantes com necessidades especiais. Com base no primeiro tópico de análise, tratando a visão de inclusão, pode-se conhecer um pouco melhor as escolas com o apoio das seguintes descrições. 
A professora S1 me explica que não tem nenhuma dificuldade em trabalhar com as alunas surdas, pois muitos de seus alunos aprenderam libras para poder se comunicar com elas e quando quer falar algo para a menina ela escreve no quadro. Em contrapartida, com a aluna com paralisia cerebral, a professora afirma que é muito complicado, pois ela não consegue "sentir" a menina em suas aulas, apesar de já ter tentado uma interação, a menina não demonstra interesse pelas atividades. (Fragmentos de entrevista)

A escola D é adaptada para alunos cadeirantes. Existem rampas de acesso para estudantes com estas necessidades especiais e também pranchas de identificação junto às cadeiras de rodas. (Fragmentos diário de campo)

A professora M diz que "para a auto-avaliação deve ser observada: criatividade, capricho, o uso do espaço na folha e o objetivo do desenho proposto na sala". Uma outra professora se aproxima e me diz que este tipo de avaliação é muito subjetiva, pois eles "não se expressam". Eles sorriem choram, gritam, mas não dá para entender o que eles querem dizer. (Fragmentos de entrevista)

Um segundo ponto pertinente a estas observações foi à formação do professor de arte. Sobre este assunto, cabe relatar algumas descrições a respeito da visão de inclusão destes docentes. Apesar de serem todos formados em artes visuais e a grande maioria aponta ter tido pouco assunto sobre inclusão na graduação. Podemos relatar acerca das variadas formas que eles receberam os alunos em suas aulas:

A professora $\mathrm{S} 1$ auxilia, a respeito da técnica, ao grupo da aluna $\mathrm{J}$ (no qual ela não está integrada), sobre a atividade que estão fazendo (...) a professora me diz que pediu para a aluna $\mathrm{J}$, que tem paralisia cerebral, participar da atividade, mas que a menina é muito acomodada, que também tem que auxiliar os outros alunos e que o tempo de uma aula (45 minutos) é muito pouco.(Fragmento de diário de campo)

A professora S2 vai até o aluno J1. A pipa que o menino tem sobre a sua carteira está pintada de azul, a docente pergunta ao menino se ele deseja que a sua pipa tenha somente a cor azul, ela mostra outras cores para ele escolher. J1 escolhe o verde, a professora o auxilia com palavras positivas; ele aponta para a professora a cor desejada e a professora tira da caixa a cor escolhida pelo menino. $\mathrm{O}$ aluno $\mathrm{J} 1$ demonstra muito esforço no seu trabalho, apesar da sua pouca coordenação nas mãos, em virtude da paralisia cerebral. Um colega de classe olha J1 pintando e fala: "olham o J1 pintando! Este olha para a turma e sorri. (Fragmentos do diário de campo)

Partindo do terceiro e quarto elemento analítico deste estudo, apresentamos aqui, além dos materiais educativos criados pelos professores, também as estratégias 
metodológicas abordadas e a arte como inclusão. Esta forma de análise está fundamentada no objetivo de diagnosticar o grau de investimento do docente na invenção e adequação de materiais para serem utilizados com os alunos com necessidades educacionais especiais e, o quanto a arte entra neste contexto como contribuição. Partindo desse ponto, vários depoimentos vão apontar para estes tópicos:

A professora S2 explica a proposta do trabalho que é recortar imagens da publicidade e propaganda. Os alunos estão divididos em grupo (...) o aluno A recorta imagens dos carros que encontra na revista. Devido a sua baixa-visão, A precisa chegar bem perto da imagem para poder recortá-la e apesar disso ele recorta direitinho. (Fragmentos do diário de campo)

A professora S1 vai até o grupo de J e dá auxílio na pintura que estão fazendo. J tem paralisia cerebral e continua não participando da atividade que seu grupo está envolvido, ela apenas olha as meninas pintarem. (Fragmentos do diário de campo)

A professora S2 vai até J1 (diagnóstico: paralisia cerebral) e explica a tarefa, coloca o lápis de cor a sua frente e pede para ele escolher as cores. S2 pede para uma menina o giz de cera, ela fala que é melhor para ele pintar com este material. S2 já trouxe o desenho da pipa ponto em uma folha, J1 pinta, a professora o auxilia com palavras positivas; “Isso J1, vamos, está ficando muito bom!”. (Fragmentos do diário de campo)

Por meio dos diários de observação pôde-se compreender as rotinas de ensino de artes visuais em classes regulares inclusivas, a diversidade de práticas docentes e as dificuldades de construir objetos pedagógicos. Quando se propôs a realização da pesquisa havia uma vaga idéia de que poucos professores de artes estariam dentro do perfil de criador de objetos pedagógicos. Por outro lado foi de fundamental importância para o avanço das pesquisas nesta área, conhecer a realidade do ensino de arte na escola.

Os diários apresentam um franco desejo de acertar a melhor atividade para trabalhar em sala de aula. Os estudantes aguçam e desafiam o processo criador dos professores de artes. Estes por sua vez apresentam com clareza a problemática que atravessam para uma inclusão de qualidade.

Os estudantes, cada um do seu modo, buscam junto com suas famílias romper a barreira da inclusão ampliando as chances de vida digna na sociedade. A arte como elemento de ampliação da capacidade simbólica constitui-se como uma área prioritária na educação de modo geral e na escola inclusiva em particular. 
O poder público como de resto nos temas sociais, ausenta-se da tarefa de investir maciçamente na educação continuada, na infra-estrutura e na efetivação de fato da legislação em vigor.

\section{Considerações Finais}

Seguramente, com base nos dados analisados, foi possível identificar as barreiras encontradas nas escolas da rede publica, quando se tratou da inclusão dos estudantes com necessidades educacionais especiais. (MENDES,2006).

Segundo, Pereira e Freitas (2006) é sabido que todos os alunos podem aprender. Com a investigação do processo de aprendizagem dos alunos A e J1, constatou-se que entre os dois estudantes observados foi possível encontrar trabalhos relativos a desenho, recorte e pintura. Verifica-se com estes dados, que se bem estimulados os estudantes com necessidades educacionais especiais poderão fazer as atividades proposta para todos os demais, ainda que com processos expressivos diferenciados. Foi verificado também que a professora destes estudantes foi à única que teve o tema da inclusão tratado em sua formação acadêmica. O dado citado acima é pertinente a esta discussão, pois foi encontrado um maior acolhimento dos alunos em aulas, cujo professor já tinha estudado o tema da inclusão. Apesar da grande receptividade das outras professoras em relação aos alunos com necessidades especiais, ainda percebe-se alguns obstáculos por parte das docentes que não tiveram este tema como fonte de estudo.

Entende-se que por meio da divulgação dos resultados desta pesquisa, a universidade poderia propor frentes de atualização que modifiquem a ação dos professores no que diz respeito à inclusão. Para concluir faz-se necessário apontar um conjunto de pesquisas que podem derivar desta como a análise da trajetória do docente em arte. Como se constituem os processos de produção artística das pessoas com necessidades especiais. Por último poderia sugerir-se a construção de objetos pedagógicos para o ensino de arte que pudessem ser testados em classes inclusivas de arte.

\section{Referências Bibliográficas:}

DIÁRIO CATARINENSE. Eficiência para alunos especiais. Na sala de Aula. Florianópolis, 18 jun. 2008, p. 6. 
contaminações. (15.:2006:Salvador)Anais do $15^{\circ}$ Encontro Nacional da ANPAP / Organizadora Cleomar de Sousa Rocha. Salvador: ANPAP, 2006.

FONSECA da SILVA, Maria Cristina da Rosa (coord). BORNELLI, Margarete Cascaes. III Jornada de Pesquisa do CEART. $17^{\circ}$ Seminário de iniciação Científica da Udesc. Florianópolis. Out/2007.

LOPES, Ana Elisabete Rodrigues de carvalho. Olhares compartilhados: o ato fotográfico como experiência alteritária e dialógica. Rio de Janeiro: PUC-Rio, 2005. 241p. Tese (Doutorado) - Departamento de Psicologia, Pontifícia Universidade Católica do Rio de Janeiro, Rio de Janeiro, 2005.

LOPES, Maura Corcini. I(M) Possibilidades de Pensar a Inclusão. $30^{\circ}$ reunião da ANPED. GT 15. Disponível em <http://www.anped.org.br/inicio.htm> Acesso em 18 de jul. de 2008.

MENDES, Enicéia Gonçalves. Inclusão: é possível começar pelas creches? $29^{\circ}$ reunião da ANPED. 2006 GT 15 Disponível em <http://www.anped.org.br/reunioes/29ra/29portal.htm.> Acesso em 18 de jul. de 2008. PEREIRA, de Abreu Janaí; FREITAS, Klix Neli. Imagens, desenhos e significados de professores e alunos com necessidade educativas especiais em escolas com educação inclusiva: o desenho como ferramenta de integração social na educação inclusiva.Ago/2006 - jul/ 2006, vol. 2, $\mathrm{n}^{\mathbf{0}} 2$ 2. Disponível em <http://www.ceart.udesc.br/revista DAPesquisa/volume2/numero2/humanas.htm> Acesso em 18 de jul. de 2008. 